\title{
CANA-DE-AÇÚCAR: BIOESTIMULANTES E ORGANOMINERAIS DE LODO DE ESGOTO
}

Emmerson Rodrigues de Moraes ${ }^{1 *}$; Rodrigo Vieira da Silva ${ }^{1}$, Brenda Ventura de Lima ${ }^{1}$, Felipe Garcia de Menezes ${ }^{1}$, Mateus Ferreira ${ }^{1}$, Aysha Cristinne dos Reis ${ }^{1}$, Joicy Vitória Miranda Peixoto ${ }^{2}$, Regina Maria Quintão Lana ${ }^{2}$

${ }^{1}$ Instituto Federal de Educação, Ciência e Tecnologia Goiano - Campus Morrinhos, Goiás. ${ }^{2}$ Universidade Federal de Uberlândia - UFU, Uberlândia, Minas Gerais. E-mail: emmerson.moraes@ifgoiano.edu.br;

\section{RESUMO}

O Brasil é o maior produtor mundial de cana-de-açúcar, a principal matéria prima utilizada para a produção de álcool e açúcar. A cultura para atingir bons níveis de produtividade demanda de altas quantidades de nutrientes, que geralmente são supridas pela o uso de fertilizantes minerais. Uma alternativa para que a adubação seja realizada de maneira eficiente é por meio da utilização de fertilizantes organominerais. Tais fertilizantes constituem-se da mistura de fertilizantes orgânicos de origem animal ou vegetal, e fertilizantes minerais que sofrem processamento industrial. 0 avanço industrial associado ao aumento populacional tem gerado grande quantidade de resíduos sólidos e águas residuárias. Uma maneira de reduzir os efeitos da poluição ambiental oriundos da presença desses resíduos sólidos é por meio do seu tratamento, dando origem a um material pastoso, conhecido como lodo de esgoto. O lodo de esgoto apresenta o potencial de ser utilizado na nutrição mineral das plantas, tanto como fertilizante quanto condicionador do solo. Os bioestimulantes são substâncias naturais ou sintéticas que podem ser aplicados diretamente nas plantas para aumentar produção e a qualidade de culturas de interesse econômico, Assim, a presente revisão tem por objetivo relatar o estudo a respeito da utilização de fertilizantes organominerais oriundos de lodo de esgoto e bioestimulante no cultivo da cana-de-açúcar.

Palavras-chave: Biossólido, Fertilidade. Produtividade. Saccharums pp.

\section{SUGARCANE: BIOSTIMULANTS AND ORGANOMINERALS OF SEWAGE SLUDGE}

\begin{abstract}
Brazil is the world's largest producer of sugarcane, the main raw material used for the production of alcohol and sugar. The crop to achieve good levels of productivity demands high amounts of nutrients, which are usually supplied by the use of mineral fertilizers. An alternative for efficient fertilization is through the use of organomineral fertilizers. Such fertilizers consist of the mixture of organic fertilizers of animal or vegetable origin, and mineral fertilizers that undergo industrial processing. The industrial advance associated with the population increase has generated a large amount of solid waste and wastewater. One way to reduce the effects of environmental pollution from the presence of these solid wastes is through their treatment, giving rise to a pasty material, known as sewage sludge. Sewage sludge presents the potential to be used in the mineral nutrition of plants, both as fertilizer and as a soil conditioner. Biostimulants are natural or synthetic substances that can be applied directly to plants to increase yield and quality of crops of economic interest. Thus, the present review aims to report the study on the use of organomineral fertilizers from sewage sludge and biostimulant in sugarcane cultivation.
\end{abstract}

Keywords: Biosolid, Fertility. Productivity. Saccharum spp. 


\section{INTRODUÇÃO}

A cana-de-açúcar (Saccharum spp.) é uma espécie vegetal semi-perene, pertencente à família Poaceae. O seu cultivo no Brasil ocorre desde os primeiros anos após a chegada dos portugueses, no início do século XVI. De origem asiática e de características de clima tropical, encontrou condições ideais para o seu desenvolvimento em extensas áreas do Brasil. $O$ açúcar foi o principal produto obtido da cana-de-açúcar, em escala mundial, até os meados do século XX. Com o surgimento da revolução industrial, houve um aumento da demanda de fontes de energia, na qual o petróleo, o carvão mineral e o gás natural foram os responsáveis pelo seu suprimento. Na década de 70 do último século, com a crise do petróleo teve o inicio a demanda por fontes de energia renováveis, a exemplo do etanol (SANTOS; BORÉM, 2016).

Desde então, apresenta-se como importante cultura fornecendo não só alimentos, mas energia renovável, fortalecendo ainda mais a economia brasileira. Ha aproximadamente um século o Brasil já possuía veículos movidos a etanol. Porém, a grande expansão dos canaviais aconteceu por volta dos anos 1970 com o surgimento do Pro-álcool. Ocorreu-se a partir deste momento uma revolução agrícola canavieira, com surgimento de novas variedades, tratos culturais, adubações, formas de colheitas e modernos sistemas de manejo. Portanto, nos dias atuais, a cultura transformou-se o setor sucroalcoleiro num dos mais importantes para a economia brasileira, com as commodities agrícolas açúcar e etanol, (SANTOS; BORÉM, 2016).

Com todo o pacote tecnológico existente na atualidade para o cultivo da cana-de-açúcar fazse vislumbrar um futuro ainda mais promissor economicamente, socialmente e ambientalmente para o planeta. A co-geração de energia e o etanol de segunda geração ou etanol celulósico são grandes exemplos (UNICA, 2013).

Neste cenário, em que a adoção de novas práticas e técnicas agrícolas tem sido feitas de forma acelerada, muitas vezes passando à frente da produção científica, faz-se necessário produzir conhecimentos que auxiliem os produtores na adoção de tecnologias sustentáveis e economicamente viáveis.

O uso do lodo de esgoto na agricultura é uma alternativa sustentável promissora para países como o Brasil. Aliada a produção de resíduos urbanos o país possui uma grande área agricultável com aproximadamente 71,7 milhões de hectares. Somente a área ocupada pela cana-de-açúcar corresponde a 9,5 milhões de hectares (IBGE, 2017). A utilização de lodo de esgoto na agricultura é uma estratégia importante para reciclagem de resíduos orgânicos originados do meio urbano. Por ser rico em matéria orgânica possui capacidade de recuperar a estrutura física e melhorar a qualidade química do solo (KULIKOWSKA; GUSIATIN, 2015).

O emprego do lodo de esgoto é uma importante matéria prima orgânica para produção de fertilizantes organominerais. Originado de resíduos, apresenta-se como alternativa sustentável para a produção agrícola. Os organominerais conferem agregação de valor agronômico aos fertilizantes. A mistura de fertilizantes minerais com orgânicos aumentam a eficiência dos mesmos e melhora a qualidade do solo. A fertilidade do solo é aumentada e o impacto ambiental é reduzido tornando-se sustentável e econômico (TEIXEIRA et al., 2014).

Algumas técnicas adicionais vem sendo utilizadas na agricultura visando aumentar quantitativamente e qualitativamente suas produções. Dentre elas esta o uso dos bioestimulantes, reguladores vegetais ou biorreguladores na cultura da cana-de-açúcar. Segundo Silva et al. (2010) "estes funcionam como ativadores do metabolismo das células, dão vigor ao sistema imunológico, reativam processos fisiológicos nas diferentes fases de desenvolvimento, estimulam o crescimento radicular, induzem a formação de novos brotos, melhoram a qualidade e quantidade do produto, etc".

Assim, a presente revisão tem como objetivo descrever os benefícios dos fertilizantes organominerais de lodo de esgoto, como uma fonte sustentável, e o bioestimulante no cultivo da cana-de-açúcar. 


\section{A cultura da cana-de-açúcar}

A cana-de-açúcar é cultivada em grande parte do território nacional. Desde sua implantação na época do Brasil colônia, tornou-se uma cultura de grande importância para o desenvolvimento econômico e social do país. A cultura tem função correlacionada com o setor agrícola para a produção de açúcar e etanol e grande participação na matriz energética brasileira para atender a demanda crescente no mercado nacional e internacional (CONAB, 2016).

Sempre haverá a necessidade de produção de energia renovável para a saúde e sustentabilidade do planeta. A cana-de-açúcar assumiu importante participação na produção de energia renovável no Brasil com o surgimento do Pro-álcool, para incentivar a produção do etanol (GONÇALVES; MENDONÇA, 2010). Outro fator importante para o crescimento da demanda de etanol foi a mudança de políticas públicas e o avanço tecnológico com o surgimento dos veículos "flex-fuel" na frota brasileira (PEREIRA; DE PAULA, 2016). Além de fonte de alimento para humanos e animais, a cultura tornou-se importante fonte de energia calórica no aquecimento das caldeiras das indústrias (LIMA JÚNIOR et al., 2014). Outra importante fonte de agregação de valor da cana-de-açúcar, oriundo de pesquisas mais recentes, é a tecnologia para produção de etanol celulósico ou de segunda geração (BRASSOLATTI et al., 2016). Além disso, vale ressaltar, outros resíduos derivados da produção de etanol, originado do caldo do colmo a exemplo da torta de filtro e vinhaça que são reciclados e utilizados como importante fonte de fertilizantes (SOUSA, 2014; BARROS et al., 2016).

Por essas razões, a cana-de-açúcar é uma das melhores opções dentre as fontes de energia renovável, com grandiosa importância para o cenário agrícola brasileiro e um futuro promissor no cenário mundial (RIBEIRO et al., 2016).

O agronegócio sucroalcooleiro movimentou aproximadamente $\mathrm{R} \$ 113$ bilhões no ano de 2015 , com faturamentos diretos e indiretos, o que corresponde a aproximadamente $8,8 \%$ do PIB nacional do agronegócio (CEPEA, 2016). Além de ser um dos setores que mais empregam no país, com a geração de cerca de (DIÁRIO PERNAMBUCANO, 2016) a 900 mil empregos diretos e congregam mais de 70 mil agricultores (JORNAL DA PARAÍBA, 2016).

A área de cana colhida destinada à atividade sucroalcooleira, na safra (2016/2017) está estimada em 9,1milhões de hectares, distribuída em todos estados produtores. O Estado de São Paulo continua sendo o maior produtor, com 52,4 \% (4.777,2 mil hectares) seguido por Goiás, com $10,5 \%$ (954,4 mil hectares), Minas Gerais com 9,4\% (855,3 mil hectares), Mato Grosso do Sul com 7,0\% (636,5 mil hectares), Paraná com 6,8\% (620,4 mil hectares), Alagoas com 3,6\% (328,8 mil hectares), Pernambuco com 2,8 \% (251,1 mil hectares), e Mato grosso com 2,5 \% (230,2 mil hectares) (CONAB, 2016).

Nos demais estados produtores as áreas são menores, mas, unidos somam-se 5,0 \% da área cultivada. A previsão do total de cana moída na safra 2016/17 é de 694,5 mil toneladas, com incremento de $4,4 \%$ em relação à safra $2015 / 16$, que foi de 665,6 mil toneladas significando que a quantidadeque será moída deve superar em 28,9 mil toneladas a moagem da safra anterior. A produtividade média brasileira está estimada em $76.232 \mathrm{~kg} \mathrm{ha}^{-1}, 0,9 \%$ menor que a da safra 2015/16 que foi de $76.903 \mathrm{~kg} \mathrm{ha}^{-1}$. Do total da cana esmagada, 326,5 mil toneladas (47 \%) serão destinadas à produção de açúcar, as quais devem produzir $39.814,8$ mil toneladas do produto. 0 restante, 368,06 mil toneladas (53 \%), serão destinadas à produção de etanol, gerando um volume total de 27.863,95 milhões de litros de etanol. Deste, 11.372,50 milhões de litros serão de etanol anidro e 16.491,44 milhões de litros serão de etanol hidratado (CONAB, 2016).

A qualidade e longevidade de um canavial está relacionado comsolos de boas propriedades químicas, físicas e biológicas. Um programa de manejo de fertilidade do solo também é uma exigência para formação de bons canaviais. Dessa forma, a adição e/ou manutenção de matéria orgânica no solo assim como níveis adequados de nutrientes são necessários para obtenção de altas produtividades. Adubações com fertilizantes organominerais contribuem para adição e 
manutenção de matéria orgânica no solo (TEIXEIRA et al., 2014). Fatores fisiológicos associados à nutricionais contribuem consideravelmente o desenvolvimento das plantas de cana-de-açúcar (MALAVOLTA et al., 1989; PEREIRA; PERES, 2016).

Dentre as estratégias de manejo diferenciadas, vale destacar o emprego de variedades adaptadas à região (LANDEL; BRESSIANI, 2010) e época adequada de plantio, o cultivo mínimo, a manutenção de palhada ou cobertura vegetal sobre o solo, o uso da gradagem e subsolagem no preparo do solo, uso de maquinário específico com rodados largos, podem proporcionar canaviais mais produtivos e prolongados (COLETI, 2010). Há usinas que realizam mais de 10 cortes ou ciclos numa mesma área sem a renovação do canavial (ARRUDA et al., 2016). Fatores extrínsecos se correlacionam com as exigências do cultivo da cana-de-açúcar, como o clima e solocontribuindo com altas produtividades, qualidade tecnológica e longos ciclos (BRUNINI, 2010; PRADO et al., 2010).

\section{Bioestimulantes vegetais}

Sabe-se que as plantas dependem dos fatores internos e externos para sobreviverem. Podemos citar os fatores externos como: luz, temperatura, pluviosidade, fotoperíodo, tipo de solo, fertilidade, etc. O fatores internos de natureza química são os que regulamentam o crescimento dos vegetais (JADOSKI et al., 2012). O mecanismo de regulação e/ou controle do desenvolvimento de animais e vegetais dependem de informações que comunicam células, tecidos e órgãos. Essas substâncias controladoras do metabolismo que emitem sinais químicos são chamados de hormônios (VIEIRA et al., 2010; RAVEN, 2014).

Os hormônios vegetais podem sem produzidos em um tecido e transportados para outro local onde terá sua ação efetivada. Também chamados de fitormônios, estes são produzidos no vegetal em diminutas quantidades em proporções muito pequenas. Um mesmo hormônio podem desencadear diferentes respostas ou reações em diferentes órgãos em diferentes fases de desenvolvimento de um vegetal. Entre os hormônios vegetais há interação, uma vez que dificilmente agem isoladamente. As auxinas, citocininas, etileno, ácido abscísico e as giberelinas são tradicionalmente os cinco fitormônios mais conhecidos. Os brassinoesteróides, ácido salicílico, ácido jasmônico e sistemina são outras substâncias que também emitem sinais químicos pesquisados recentemente (RAVEN, 2014).

Assim, hormônio vegetal é um composto natural produzido na planta com características orgânicas. Os reguladores vegetais ou biorreguladores são substâncias sintéticas que são administradas ao vegetal. Os estimulantes vegetais ou bioestimulantes é a mistura formada entre reguladores ou com outros compostos de natureza bioquímica como aminoácidos, nutrientes e outros ingredientes ativo contribuinte com o desenvolvimento vegetal (VIEIRA et al., 2010).

\section{Auxinas}

Charles Darwin e seu filho Francis em seu livro publicado em 1881 mencionaram estudos envolvendo reguladores de crescimento. Alguns anos depois em 1926 Frits W. Went viera a designar a substância que envolvia seus estudos de auxina. Assim, foi o primeiro fitormônio descrito na literatura (RAVEN, 2014). Os tecidos meristemáticos das plantas são os principais sítios de produção, seja em vias aéreas ou subterrâneas. Dependendo dos tecidos ou locais de produção há grandes variações das quantidades produzidas (VIEIRA et al., 2010).

A auxina ácido indol-3-acético (AIA) é um dos principais hormônios vegetais. Produzido no vegetal possuem grande capacidade de influenciar no crescimento das plantas e iniciação da atividade cambial e dominância apical(REZENDE et al., 2011). O AIA regula a divisão celular e expansão, diferenciação vascular, desenvolvimento de raízes laterais e dominância apical (TAIZ; ZEIGER, 2009). Pode-se citar também o indol-3-butírico (IBA), ácido 4-cloroindolo-3-acético (4-ClIAA) e ácido fenilacético (PAA) como auxinas vegetais (VEGA-CELEDÓN et al., 2016). Lisboa et al. 
(2014) verificaram resultado viável para o desenvolvimento de calos de cana-de-açúcar utilizando 0,125 mg/l de 2,4-D e concluíram que a auxina diminui o diâmetro da célula e do seu núcleo.

\section{Cinetina}

As citocininas começaram a ser descobertas por Johannes van Overbeek por volta e 1941 quando observou que água de coco (Cocos nucifera) promovia desenvolvimento embrionário e crescimento de células e tecidos. $O$ uso da citocinina isolada na tem pouco ou nenhum efeito. Sua ação esta intimamente relacionada com as auxinas. Com a união dos dois hormônios há uma rápida divisão celular formando grande número de células pequenas e indiferenciadas. Porém tudo será dependente das concentrações e proporção de ambos os hormônios. Em altas concentrações de auxinas haverá grande formação de raízes. O inverso quando em altas concentrações de cinetina haverá crescimento de gemas (REZENDE et al., 2011; RAPOSO et al., 2013). Em concentrações iguais há produção de células meristemáticas.

Em Arabidopsis sp. ao controlar a velocidade de diferenciação e divisão celular a citocinina determina o tamanho do meristema radicular. Desta forma, há um balanceamento dos efeitos da auxina que é responsável por controlar a divisão celular (RAVEN, 2014). As citocininas ainda retardam o envelhecimento das folhas evitando sua senescência prolongando sua etapa útil na planta (REZENDE et al., 2011). Raposo et al. (2013) comparando meios de cultura para cana-deaçúcar notaram que a adição de cinetina à água de coco promovem regeneração e crescimento celular de cana-de-açúcar.

\section{Giberelina}

As giberelinas foram descobertas por cientistas japoneses em 1926. Estas substâncias estão presentes em praticamente todas as plantas sendo encontradas 136 giberelinas naturais. O Ácido giberélico é a giberelina mais estudada produzida pelo fungo Gibberella fujikuroi. Por promover a divisão e alongamento celular causam perceptíveis alongamentos dos caules, raízes, folhas e frutos. São eficientes para superar dormência e promover a germinação das sementes (RAVEN, 2014). Campus et al. (2015) observaram aumentos lineares no crescimento de raízes e da parte aérea de plântulas de biribá promovendo melhor desenvolvimento.

\section{Interação auxina, cinetina e giberelina}

Mistura de hormônios vegetais cinetina, ácido giberélico eácido 4-indol-3-ilbutírico (AIB) transforma-se em estimulante vegetal (bioestimulante) de grande capacidade de favorecer um adequado equilíbrio hormonal. Em função de suas propriedades químicas podem incrementar o crescimento, desenvolvimento e produção. Estimulam a divisão, diferenciação e alongamento celular, melhorando o crescimento e desenvolvimento radicular (SILVA et al., 2010). Dessa forma, a capacidade de exploração do solo e absorção de água e nutrientes é maximizada. Auxiliana eficiência da germinação de sementes, aumenta o vigor inicial, crescimento e desenvolvimento radicular e foliar. Ainda, favorece a produção de compostos orgânicos que contribuirão significativamente para ocorrência de altos índices de produção e qualidade da produção das plantas (MUCHALAK et al., 2016).

\section{Uso de lodo de esgoto}

Atualmente, o uso na agricultura de lodo de esgoto, oriundo de residências urbanas e industriais está crescendo substancialmente. Novas Estações de Tratamento de Esgoto (ETEs) estão sendo construídas e as existentes estão expandindo sua capacidade. A preocupação ambiental também é crescente, surgindo tecnologias para o uso desse tipo de resíduos como fonte de nutriente (TSUTIYA, 2001). O lodo de esgoto higienizado ou biossólido é composto por matéria orgânica, nutrientes e alguns elementos potencialmente tóxicos. Além do lodo o 
tratamento de esgotos gera, também águas residuais com baixa carga poluidora. A disposição adequada deste resíduo é um dos principais desafios a ser enfrentado pelos gestores ambientais (GALDOS et al., 2004).

O lodo de esgoto é um resíduo sólido pastoso resultante das ETEs. Toneladas desse produto são produzidos em estações de tratamento de esgoto (MAPA, 2009; RESENDE JÚNIOR et al., 2016), para o qual é preciso dar um destino correto, principalmente do ponto de vista ambiental. A utilização do lodo de esgoto na agricultura destaca-se como prática viável do ponto de vista ambiental, social, agronômico e econômico (DEEKS et al., 2013). É uma prática comum em países desenvolvidos, sendo utilizado por agricultores a mais de 50 anos (SANEPAR, 1999). Além disso, a utilização agrícola de lodo de esgoto está de acordo com a agenda 21, negociada na Conferência Mundial de Meio Ambiente, que estimula a minimização da produção de resíduos e sempre que possível, a reciclagem de resíduos (AGENDA 21, 1995).

Apesar da resposta no desenvolvimento e produtividade de diversas culturas, por se tratar de um resíduo urbano-industrial, há necessidade de seguir critérios rigorosos para sua aplicação na agricultura, haja vista que em sua composição existem poluentes como metais pesados, compostos orgânicos e micro-organismos patogênicos ao homem (ROCHA et al., 2003). Quando incorporado ao solo, o lodo de esgoto proporciona alterações em propriedades físicas, como a densidade do solo, tamanho dos agregados e capacidade de retenção de água; em propriedades químicas, como o pH, condutividade elétrica, capacidade de toca catiônica e aumento dos teores de fósforo e nitrogênio; e em propriedades biológicas, geralmente incrementando a atividade microbiana do solo, quando não apresenta limitações com elementos tóxicos e metais pesados (MARTINS et al., 2015).

A utilização do lodo de esgoto já foi estudada em diversas culturas. Em estudos realizados por Rabello (2013) observou-se que a produção de azevém tratado com biossólidos a partir de 25 $\%$ de adição de lodo de esgoto foi superior aos tratamentos contendo somente solo. Silva et al. (2008) avaliaram o efeito da adição de diferentes doses dos lodos de esgoto úmido (torta) e seco (granulado) complementados com potássio e boro e aplicados ao solo nas linhas de plantio em parcelas experimentais de Eucalyptus grandis. Dezoito meses após a implantação das mudas no campo, o volume dos troncos demonstrou aumento significativo de aproximado de $130 \%$ ao crescimento dos eucaliptos tratados com os biossólidos úmido e seco em relação à testemunha sem aplicação de fertilizante, bem como teve resultado semelhante ao do tratamento com adubo mineral. Lemainskie Silva (2006) concluíram que o aproveitamento do biossólido como fertilizante na cultura da soja é viável em termos agronômicos e econômicos, sendo que o efeito residual do biossólido úmido na soja é evidenciado no segundo cultivo, além de ser, em média, 18\% mais eficiente do que o fertilizante mineral como fonte de nutrientes para a cultura. Rocha et al. (2003) observaram maior produtividade em couve adubada com lodo de esgoto quando comparadas com aquelas adubadas com esterco.

A resolução CONAMA № 375/2006, impõe normas e critérios na utilização do lodo de esgoto na agricultura. $\mathrm{O}$ artigo 2 o determina que o lodo de esgoto seja tratado ou higienizado para fins de uso em culturas agrícolas ou florestais. Estes são processos de estabilização, extermínio ou redução de patógenos, redução do poder de atração de vetores de moléstias. $\mathrm{O}$ artigo 5 diz que o lodo de esgoto para uso agrícola deve-se atender a limites mínimos das substâncias ou elementos potencialmente tóxicas. No artigo 10 cita-se o monitoramento anual ou até mesmo de áreas de ocorrência da aplicação do lodo de esgoto.

Atendendo resolução CONAMA № 375/2006 o lodo de esgoto deve passar por um processo de higienização ou compostagem para se tornar um biossólido. Dessa forma, ocorrerá uma redução do volume da massa de resíduo, eliminação ou redução extrema de patógenos nocivos, redução do volume de água, reduzir ou eliminar poluentes orgânicos ou inorgânicos como metais pesados (KULIKOWSKA; GUSIATIN, 2015). Dentre outras formas de higienização o lodo de esgoto 
centrifugado pelas ETEs é tratado com adição de cal hidrata e submetido a raios ultravioletas solares sob condição de estufa. Posteriormente desidratado a ponto de manipulação na forma de sólido (RESENDE JÚNIOR et al., 2016).

Os fertilizantes organominerais passam por processo físico-químico-mecânico de digestão que eliminam os microorganismos patogênicos tornando-o isento de patógenos e sementes viáveis de ervas daninhas. $\mathrm{O}$ processo demanda de temperaturas de aproximadamente $70^{\circ} \mathrm{C}$ e pressão para formar os pellets. Assim há um aumento da segurança em seu uso na agricultura (OLIVEIRA, 2014). Nesse sentido, há uma grande possibilidade de estar submetendo o lodo de esgoto a um processo industrial de rotina para estar produzindo os organominerais transformando-o em fertilizante organomineral descontaminado. Por sem uma matéria prima oriunda de resíduos urbanos há um ganho muito grande em sustentabilidade.

\section{Fertilizantes organominerais}

Os fertilizantes organominerais é uma mistura formada por fertilizantes de fração orgânicae mineral. Sua utilização para aplicação nos solos é dependente de especificações próprias e garantias mínimas. Os fertilizantes organominerais sólidos deverão apresentar um mínimo de: 8 \% de carbono orgânico; $80 \mathrm{mmol}_{\mathrm{c}} \mathrm{kg}^{-1} ; 10 \%$ de macronutrientes primários isolados $(\mathrm{N}, \mathrm{P}, \mathrm{K})$ ou em mistura (NK, NP, PK, NPK); $5 \%$ de macronutrientes secundários; $1 \%$ de micronutrientes e $30 \%$ de umidade máxima (MAPA, 2009).

O fertilizante organomineral pode ser produzindo a partir da mistura física das fontes orgânica com a mineral originando o organomineral farelado apto ao fornecimento às culturas. As duas matérias primas poderão, após a homogeneização passar por um processo de peletização por extrusão. Apeletização por extrusão é o processo pelo qual o fertilizante passa em curto espaço de tempo por alta pressão, umidade e temperatura (AMARAL, 2002; OLIVEIRA, 2014) produzindo pellets com elevado grau de dureza $\left(8,0 \mathrm{~kg} \mathrm{~cm}^{-2}\right)$ (TEIXEIRA, 2013). Este autor afirma que o fertilizante adquire alta resistência a fragmentação evitando segregação dos componentes. Ferreira (2014) afirma que os fertilizantes organominerais podem melhorar a eficiência agronômica das adubações. Estes reduzem o processo natural de fixação do fósforo lábil fornecido ao solo estando prontamente disponível às plantas por um tempo mais longo. Ainda, componentes minerais muito móveis no solo como nitrogênio e boro são liberados de forma mais lenta possibilitando maior aproveitamento das plantas.

Dentre as matérias primas que podem ser utilizadas na mistura ou processamento de um fertilizante organomineral, estão: lodo de esgoto, cama ou esterco de galinha, estercos de bovino, e de suíno, torta de mamona, torta de filtro oriundos do processamento de etanol e açúcar, adubos verdes, turfa, compostos orgânicos, resíduos do processamento de frutos (SOUSA, 2014).

Sousa (2014) ao pesquisar fertilizante organomineral para a produção de cana-de-açúcar, concluiu que a eficiência na utilização dos nutrientes aplicados do fertilizante organomineral foi maior quando comparado ao fertilizante mineral na maioria das doses avaliadas. Teixeira (2014) também observou maior eficiência em doses de fósforo fornecidas por fertilizante organomineral na cultura da cana-de-açúcar. Corrobora os resultado de, Sousa (2014) em que o fertilizante organomineral, além de ser mais eficiente tanto em cana planta quanto em cana soca, pode substituir o fertilizante mineral incrementando uma eficiência de até $24 \%$ de produção de colmos. Branco (2012) comenta alguns "benefícios sustentáveis dos fertilizantes organominerais". Dentre eles, a capacidade de recuperação da flora microbiana; a redução da acidificação do solo e a liberação gradativa de nutrientes. Tais benefícios influenciarão no melhor desenvolvimento do sistema radicular; menor fixação de fósforo aos colóides do solo e maior absorção de água. Para Sousa (2014) o custo operacional da lavoura terá redução por diminuir operações de calagens e fertilizantes mineral e orgânico em conjunto ao longo dos cultivos. 
A partir do desenvolvimento agropecuário no século XXI, iniciou-se o aumento do descarte de resíduos agropecuários. Assim, agricultores iniciaram a reutilização ou ciclagem em maiores proporções. Percebendo os grandes benefícios dos fertilizantes orgânicos uniram-se as vantagens do fertilizantes minerais. Porém, a viabilidade econômica de aplicação de grandes volumes de fertilizantes orgânicos em extensas áreas é baixa. A adição de componente minerais enriquece a mistura proporcionando a redução de grandes volumes e custos. Gargalos como logística, disponibilidade de matéria prima apta ao enriquecimento com fonte mineral, infra-estrutura de produção são fatores reais que os agricultores e as empresas do setor enfrentam. $O$ conhecimento da composição e a manipulação dos resíduos constitui-se em barreiras que dificultam o processo. Há várias fontes orgânicas, dentre elas o próprio lodo de esgoto, porém este é dotado de vários critérios rigorosos para a sua utilização, tornando-se uma dificuldade. Diante do exposto, ainda, vale salientar que falta mais incentivos governamentais como financiamentos e subsídios, onde empresas privadas possam investir na ciclagem de resíduos, principalmente o lodo de esgoto (ROYO, 2010).

\section{CONSIDERAÇÕES FINAIS}

A nutrição adequada de um canavial é muito importante para obtenção de altas produtividades da cultura (ORLANDO FILHO, 1993). Por meio da utilização de bioestimulantes e fertilizantes organominerais de lodo de esgoto e sua associação, destaca-se a importância global do aperfeiçoamento e uso desta tecnologia. Os ganhos em produtividade dos canaviais são notórios. Ademais, os grandes ganhos advém da construção e manutenção de um solo fértil (LANA et al., 2016) da ciclagem de nutrientes essenciais que são descartados como resíduos. Ainda, da redução de contaminantes de mananciais e do subsolo, da redução da emissão de gases causadores de efeito estufa, além da redução de ambientes proliferadores de doenças e seus respectivos vetores. Enfim, são grandes os ganhos ambientais, econômicos e sociais da utilização desta prática agrícola no cultivo da cana-de-açúcar.

\section{AGRADECIMENTOS}

Ao Conselho Nacional de Desenvolvimento Científico e Tecnológico (CNPq); A Fundação de Amparo à Pesquisa do Estado de Minas Gerais - FAPEMIG; Companhia Mineira de Açúcar e Álcool (CMAA) - Vale do Tijuco; Araporã Bioenergia, Stoller do Brasil e ao Instituto Federal Goiano Campus Morrinhos.

\section{REFERÊNCIAS}

AGENDA 21 - Conferência das nações unidas sobre o meio ambiente e desenvolvimento. Brasília: Câmara dos Deputados, Coordenação de Publicações, 1995. 471p.

AMARAL, C. M. C. do. Extrusão e peletização de ração completa: efeitos no desempenho, na digestibilidade e no desenvolvimento das câmaras gástricas de cabritos saanen. 2013. $71 f$. (Mestrado em Zootecnia/Produção animal) - Universidade Estadual Paulista, Jaboticabal SP/Brasil.

ARRUDA, E. M.; DE ALMEIDA, R. F.; DOMINGUES, L. A. da S.; DA SILVA JÚNIOR, A. C.; DE MORAES, E. R.; BARROS, L. R.; SOUSA, J. L. de O.; LANA, R. M. Q. Soil porosity and density in sugarcane cultivation under different tillage systems. African Journal of Agricultural Research. v. 11, n.30, p. 2689-2696, 2016. https://doi.org/10.5897/AJAR2015.10608 
BARROS, V. G.; DUDA, R. M.; DE OLIVEIRA, R. A. Reatores UASB mesofílicos em série para produção de biogás utilizando vinhaça com torta de filtro. Ciência \& Tecnologia: Fatec-JB, Jaboticabal, v. 8, Suplemento, 2016.

BRANCO, G. Benefícios sustentáveis dos fertilizantes organominerais. Força e união da indústria de tecnologia e nutrição. Associação Brasileira das Indústrias de Tecnologia em Nutrição Vegetal. ABISOLO, Agroanalysis, 2012.

BRASSOLATTI, T. F. Z.; HESPANHOL, P. A.; COSTA, M. A. B.; BRASSOLATTI, M. Etanol de Primeira e Segunda Geração. Revista Interdisciplinar de Tecnologias e Educação. v. 2, n 1, 2016.

BRUNINI, O. Ambientes climáticos e exploração agrícola da cana-de-açúcar. In: DINARDOMIRANDA, L. L.; VASCONCELOS, A. C. M. de; LANDELL, M. G. de A. Cana-de-açúcar. Campinas: Instituto Agronômico ,1 ed., 2010, 882p.

CAMPUS, L F. C.; ABREU, C. M. de; GUIMARÃES, R. N.; SELEGUINI, A. Escarificação e ácido giberélico na emergência e crescimento de plântulas de biribá. Ciência Rural, Santa Maria, v.45, n.10, p.1748-1754, 2015. https://doi.org/10.1590/0103-8478cr20140249

CEPEA - Centro de Estudos Avançados em Economia Aplicada. Departamento de Economia, Administração e Sociologia. ESALQ - Escola Superior de Agricultura Luiz de Queiroz, USP Universidade de São Paulo. 2016. Disponível em: <http://www.cepea.esalq.usp.br/br/pib-doagronegocio-brasileiro.aspx>. Acessado em $11 \mathrm{de} \mathrm{fev.} \mathrm{de} 2017$.

COLETI, J. T. Tratos culturais na cana soca. In: DINARDO-MIRANDA, L. L.; VASCONCELOS, A. C. M. de; LANDELL, M. G. de A. Cana-de-açúcar. Campinas: Instituto Agronômico ,1 ed., 2010, 882p.

CONAMA - Conselho Nacional do Meio Ambiente. Resolução no 375 , de 29 de agosto de 2006.

DEEKS, L. K.; CHANEY, K.; MURRAY, C.; SAKRABANI, R.; GEDARA, S.; LE, M. S.; TYRREL, S.; PAWLETT, M.; READ, R.; SMITH, G. H. A new sludge-derived organo-mineral fertilizer gives similar crop yields as conventional fertilizers. Agronomy for Sustainable Development. v. 33, n. 3., p.539-549, 2013. https://doi.org/10.1007/s13593-013-0135-z

DIÁRIO PERNAMBUCAO. Brasil é líder na geração de empregos em biocombustíveis. 2016. Disponível em: <http://www.impresso.diariodepernambuco.com.br/app/noticia/cadernos/economia/2016/09/10 /interna_economia,153535/brasil-e-lider-na-geracao-de-empregos-em-biocombustiveis.shtml>. Acessado em 11 de fev. de 2017.

GALDOS, M. V.; DE MARIA, I. C.; CAMARGO, O. A. Atributos químicos e produção de milho em um Latossolo Vermelho eutroférrico tratado com lodo de esgoto. Revista Brasileira de Ciência do Solo, v. 28, n. 3, p569-577, 2004. https://doi.org/10.1590/S0100-06832004000300017

GONÇALVES, R. J. de A. F.; MENDONÇA, M. R. Modernização energética e desenvolvimento do setor sucroalcooleiro: reestruturação produtiva do capital e precarização do trabalho nas áreas de Cerrado. Revista Percurso - NEMO, Maringá, v. 2, n. 1, p.53-72, 2010. 
IBGE - Instituto Brasileiro de Geografia e Estatística. 2017. Disponível em: <http://www.ibge.gov.br/home/estatistica/indicadores/agropecuaria/Ispa/lspa_201701_1.shtm>. Acessado em 10 de fev. de 2017.

JADOSKI, C. J.; TOPPA, E. V. B.; RODRIGUES, J. D. Desenvolvimento mofofisiológico de raízes e brotos da cana-de-açúcar (Saccharum officinarum L.). Scientia Agraria Paranaenis. v. 11, n. 2, p 2232, 2012. https://doi.org/10.18188/1983-1471/sap.v11n2p22-32

JORNAL DA PARAÍBA. Setor da cana-de-açúcar gera 900 mil empregos diretos. 2016. Disponível em:

<http://www.ibge.gov.br/home/estatistica/indicadores/agropecuaria/Ispa/Ispa_201701_1.shtm>. Acessado em 11 de fev. de 2017.

KULIKOWSKA, D.; GUSIATIN, Z. M. Sewage sludge composting in a two-stage system: Carbon and nitrogen transformations and potential ecological risk assessment. Waste Management, v. 38, p. 312-320, 2015. https://doi.org/10.1016/j.wasman.2014.12.019

LANA, R. M. Q.; MAIA, L. O. R.; VASCONCELOS, A. C. P. de; MORAES, E. R. de; SIQUEIRA, T. P.; SILVA, A. de A. Evaluation of chemical attributes of soil under different management systems of sugarcane in an area of expansion. Bioscience journal, Uberlândia, v. 32, n. 3, p. 611-618, 2016.

LANDELL, M. G. de A.; BRESSIANI, J. A. Melhoramento genético, caracterização e manejo varietal. In: DINARDO-MIRANDA, L. L.; VASCONCELOS, A. C. M. de; LANDELL, M. G. de A. Cana-de-açúcar. Campinas: Instituto Agronômico ,1 ed., 2010, 882p.

LEMAINSKI, J.; SILVA, J. E. da. Avaliação agronômica e econômica da aplicação de biossólido na produção de soja. Pesquisa agropecuária brasileira, v.41, n. 10, p.1477-1484, 2006. https://doi.org/10.1590/S0100-204X2006001000004

LIMA JÚNIOR, C.; SAMPAIO, E. V. de S. B.; LIMA, R. L. F de A.; MENEZES, R. S. C. Potencial de Aproveitamento Energético de Fontes de Biomassa no Nordeste do Brasil. Revista Brasileira de Geografia Física, v.07, n. 02, 2014, 207-221.

LISBOA, L. A. M.; VentuRA, G.; ChAGAS, A. T.; VIANA, R. da S.; FIGUeiRedo, P. A. M. de. Concentrações de 2,4-D para o desenvolvimento de calos de meristemas de cana-de-açúcar. Ciência \& Tecnologia: Fatec-JB, Jaboticabal, v. 6, p. 187-191, 2014. Suplemento.

MALAVOlTA, E.; VITTI, G. C.; OLIVEIRA, S. A. de. Avaliação do estado nutricional das plantas: princípios e aplicações. Piracicaba: POTAFOS, 1989. 201p.

MAPA - Ministério da agricultura, pecuária e abastecimento. Secretaria de defesa agropecuária. Instrução normativa no 25, de 23 de julho de 2009.

MARTINS, B. H. da S.; MARTINEZ, D. G.; PUIG, P.; BANDAR, H. A.; SCHIMITZ, W. C. Uso de Biossólido na Agricultura. Revista Brasileira de Energias Renováveis, v.4, p. 64-72, 2015.

MELO, W. J.; MARQUES, M. O.; MELO, V. P. O uso agrícola do biossólido e as propriedades do solo. In: TSUTIYA, M. T. et al. Eds. Biossólidos na agricultura. São Paulo: Sabesp, 2001. 
MUCHALAK, S. M.; CUNHA, F. F. da; GUAZINA, R. A.; LIMA, S. F. de; GODOY, A. R. Utilização de bioestimulante nas características agronômicas de diferentes cultivares de batata irrigada. Núcleos, v.13, n.2, 2016.

OLIVEIRA, G. R. de. Validação do processo de digestão e de peletização de cama de aviário para a produção de fertilizante organomineral. 2014. 211 fls. Tese (Doutorado em Engenharia de Bioprocessos e Biotecnologia) - Universidade Federal do Paraná, Curitiba.

PEREIRA, W.; DE PAULA, N. Fomento federal ao etanol de segunda geração no brasil: um exame da atuação da FINEP e do BNDES. Revista de políticas públicas. v. 20, n. 2, 2016. https://doi.org/10.18764/2178-2865.v20n2p805-824

PEREIRA, F. B.; PERES, F. S. B. Nutrição e enraizamento adventício de plantas lenhosas. Pesquisa Florestal Brasileira, Colombo, v. 36, n. 87, p. 319-326, 2016. https://doi.org/10.4336/2016.pfb.36.87.1146

PRADO, H. do; JÚNIOR, A. L. P.; GARCIA, J. C.; MORAES, J. F. L. de; CARVALHO, J. P. de; DONZELI, P. L. Solos e ambientes de produção. In: DINARDO-MIRANDA, L. L.; VASCONCELOS, A. C. M. de; LANDELL, M. G. de A. Cana-de-açúcar. Campinas: Instituto Agronômico ,1 ed., 2010, 882p.

RABELLO, R. V. Estudo do efeito de diferentes doses de biossólido sobre o desenvolvimento de azevém (Lolium multiflorum Lam Semilla). 2013. 86 f. (Trabalho conclusão de curso/Engenharia Ambiental). Universidade do Vale do Itajaí, Itajaí - SC/Brasil.

RAPOSO, M. S.; GOIA, T. G.; NASCIMENTO, D. D. do; OLIVEIRA, E. T. de. Comparação de meios de cultura para organogênese direta de cana-de-açúcar (Saccharum spp.). Bioenergia em Revista: diálogos, v 3, n. 1, p. 9-19, 2013.

RAVEN, P. H. Biologia vegetal. Rio de Janeiro - RJ, Guanabara Koogan, 8. ed., 2014. 1637p.

RESENDE JÚNIOR, J. C. de; CAMARGO, de R.; LANA, R. M. Q.; FILHO, A. A.; MATOS, A. L. A. The effects of sewage sludge, mineral and organic fertilizers on initial growth of Urochloa brizantha $\mathrm{cV}$ Marandu (Hochst. ex A. Rich.) R. D Webster. African Journal of Agricultural Research. v. 11, n. 36, p. 3460-3470, 2016. https://doi.org/10.5897/AJAR2016.11477

Rezende, J. C. de; CARVAlho, C. H. S. de; SANTOS, A. C. R.; PASQuAL, M.; MENDES, A. N. G. Influência de auxina e citocinina no desenvolvimento de embriões somáticos de Coffea arabica $\mathrm{L}$. Plant Cell Culture Micropropagation, Lavras, v.7, n.1, p. 1-8, 2011

RIBEIRO, N. V.; FERREIRA, L. G.; FERREIRA, N. C. Avaliação da expansão do cultivo da cana-deaçúcar no bioma cerrado por meio de modelagem dinâmica da paisagem. Revista Brasileira de Cartografia. v. 68, n. 1, 1-14p., 2016.

ROCHA, R. E. M. da; PIMENTEL, M. S.; ZAGO, V. C. P.; RUMJANEK, N. G.; DE-POLLI, H. Avaliação de biossólido de águas servidas domiciliares como adubo em couve. Pesquisa agropecuária brasileira,Brasília, v. 38, n.12, 2003.

ROYO, J. Resíduos animais para fertilizantes organominerais. Combinação dos restos de suínos e aves com adubos minerais viabiliza a produção de orgânicos em grande escala e evita passivos 
ambientais. Jornal dia de campo. 2010. Disponível em: <http://www.diadecampo.com.br/zpublisher/materias/Materia. asp?id=22849\&secao=Pacotes\%2 OTecnol\%F3gicos>. Acessado em 24 de fev. de 2017.

SANEPAR - Companhia de saneamento do Paraná. Uso e manejo do lodo de esgoto na agricultura. Curitiba - PR/Brasil, 1999, 98p.

SANTOS, F.; BORÉM, A. Cana-de-açúcar: do plantio a colheita. Viçosa, MG: Ed. UFV, 2016. 290p.

SILVA, M. de A.; CATO, S. C.; COSTA, A. G. F. Produtividade e qualidade tecnológica da soqueira de cana-de-açúcar submetida à aplicação de biorregulador e fertilizantes líquidos. Ciência Rural, v.40, n.4, abr, 2010. https://doi.org/10.1590/S0103-84782010005000057

SILVA. P. H. M. da; POGGIANI, F.; GONÇALVES, J. L. de M.; STAPE, J. L. Volume de madeira e concentração foliar de nutrientes em parcelas experimentais de Eucalyptus grandis fertilizadas com lodos de esgoto úmido e seco. Revista Árvore, Viçosa, v.32, n. 5, 2008

SOUSA, R. T. X. de. Fertilizante organomineral para a produção de cana-de-açúcar. 2014. 87f. (Doutorado em Agronomia/Fitotecnia) - Universidade Federal de Uberlândia, Uberlândia MG/Brasil.

TAIZ, L.; ZEIGER, E. Fisiologia vegetal. Porto Alegre: Artmed, 2009. 819p.

TEIXEIRA, W. G. Biodisponibilidade de fósforo e potássio provenientes de fertilizantes mineral e organomineral. 2013. 115f. (Mestrado em Agronomia/Solos) - Universidade Federal de Uberlândia, Uberlândia - MG/Brasil.

TEIXEIRA, W. G.; SOUZA, R. T. X. de; KORNDÖRFER, G. H. Response of sugarcane to doses of phosphorus providedby organomineral fertilizer. Bioscience Journal, Uberlândia, v. 30, n. 6, p. 1729-1736, 2014.

TSUTIYA, M. T. Alternativas de disposição final de biossólidos. In: TSUTIYA, M. T.; COMPARINI, J. B.; SOBRINHO, P. A.; HESPANHOL, I.; CARVALHO, P. C. T.; MELFI, A. J.; MELO, W. J.; MARQUES, M. O., eds. Biossólidos na agricultura. São Paulo, SABESP, 2001. 468p.

UNICA - União da Indústria de cana-de-açúcar. Usina pioneira de etanol celulósico coloca Brasil entre líderes globais no uso da nova tecnologia. 2013. Disponível em: <http://www.unica.com.br/noticia/29810917920343378786/usina-pioneira-de-etanol-celulosicocoloca-brasil/>. Acessado em 06 de jan. de 2017.

VEGA-CELEDÓN, P.; MARTíNEZ, H. C.; GONZÁLEZ, M.; SEEGER, M. Biosíntesis de ácido indol-3acético y promoción del crecimiento de plantas por bacterias. Cultivos Tropicales. v.37, supl. 1, La Habana, 2016.

VIEIRA, E. L.; DE SOUZA, G. S.; DOS SANTOS, A. R.; SILVA, J. dos S. Manual de fisiologia vegetal. São Luis - MA, EDUFMA, 2010, 230p. 